This item was submitted to Loughborough's Research Repository by the author.

Items in Figshare are protected by copyright, with all rights reserved, unless otherwise indicated.

\title{
Faecal sludge in Accra, Ghana: problems of urban provision
}

PLEASE CITE THE PUBLISHED VERSION

https://doi.org/10.2166/wst.2009.441

PUBLISHER

(c) IWA PUBLISHING 2009

\section{VERSION}

AM (Accepted Manuscript)

\section{PUBLISHER STATEMENT}

This work is made available according to the conditions of the Creative Commons Attribution-NonCommercialNoDerivatives 4.0 International (CC BY-NC-ND 4.0) licence. Full details of this licence are available at: https://creativecommons.org/licenses/by-nc-nd/4.0/

\section{LICENCE}

CC BY-NC-ND 4.0

\section{REPOSITORY RECORD}

Boot, Niall L., and Rebecca E. Scott. 2019. "Faecal Sludge in Accra, Ghana: Problems of Urban Provision". figshare. https://hdl.handle.net/2134/34295. 


\section{Editorial Manager(tm) for Water Science and Technology Manuscript Draft}

Manuscript Number: WST-WSTWS-EM08256R1

Title: Faecal sludge in Accra, Ghana: problems of urban provision

Article Type: Research Paper

Keywords: bucket latrines; faecal sludge management; partnership; urban

Corresponding Author: Ms Rebecca Elizabeth Scott, MSc (Eng)

Corresponding Author's Institution: Loughborough University

First Author: Niall L Boot, MSc

Order of Authors: Niall L Boot, MSc; Rebecca E Scott, MSc (Eng)

Manuscript Region of Origin: GHANA

Abstract: Urban on-site sanitation services presents challenges for emptying, transporting, disposing and treating faecal waste. Transfer stations can be used by household-level emptiers to safely dispose of faecal sludge, but they rarely exist. Accra's use of transfer stations has provided an opportunity to research their functioning, as part of broader faecal sludge management arrangements.

The paper discusses the benefits offered by use of transfer stations, as well as reasons currently limiting their operation. While costs associated with operating and emptying these stations are passed to householders, an illegal sector thrives offering lower cost emptying services, typically with disposal of faecal sludge directly into the environment.

At present, bucket latrines offer sanitation services to low-income households unable to afford higher service levels, such as septic tanks. The local government aims to phase-out all bucket latrines by 2010, but affordable alternatives have not been found. Where limited access to land inhibits investment in permanent facilities, families may abandon household sanitation altogether.

The paper concludes that correct use of transfer stations can provide improvements for existing faecal sludge management and reduce indiscriminate dumping. They must be made available to all workers, through effective public-private arrangements for ownership and operation. 


\title{
Faecal sludge in Accra, Ghana: problems of urban provision
}

\author{
N. L. D. Boot* and R. E. Scott** \\ *GOAL, Sierra Leone (research conducted whilst MSc student at WEDC) \\ E-mail: niallboot@gmail.com \\ **Water, Engineering and Development Centre (WEDC), Loughborough University, UK. \\ E-mail: r.e.scott@Lboro.ac.uk
}

\begin{abstract}
Urban on-site sanitation services present challenges for emptying, transporting, disposing and treating faecal waste. Transfer stations can be used by household-level emptiers to safely dispose of faecal sludge, but they rarely exist. Accra's use of transfer stations has provided an opportunity to research their functioning, as part of broader faecal sludge management arrangements.

The paper discusses the benefits offered by use of transfer stations, as well as reasons currently limiting their operation. While costs associated with operating and emptying these stations are passed to householders, an illegal sector thrives offering lower cost emptying services, typically with disposal of faecal sludge directly into the environment.
\end{abstract}

At present, bucket latrines offer sanitation services to low-income households unable to afford higher service levels, such as septic tanks. The local government aims to phase-out all bucket latrines by 2010 , but affordable alternatives have not been found. Where limited access to land inhibits investment in permanent facilities, families may abandon household sanitation altogether.

The paper concludes that correct use of transfer stations can provide improvements for existing faecal sludge management and reduce indiscriminate dumping. They must be made available to all workers, through effective public-private arrangements for ownership and operation.

Keywords: bucket latrines; faecal sludge management; partnership; urban

\section{INTRODUCTION}

Provision of adequate, safe and sustainable latrine coverage is an ever-increasing challenge facing urban areas of low income countries. As urban migration increases, available latrines are receiving more and more users, while an increase in population density reduces the space available to build latrine structures and relocate these structures as pits become full. This has led to growing interest in approaches to safe emptying, transport and disposal of faecal sludge, within the broad context of Faecal Sludge Management (FSM) (Strauss and Montangero, 2002).

\section{Background to faecal sludge management}

Numerous technical developments have attempted to address the problems of emptying, transport and disposal of faecal sludge from urban centres. However, the massive challenge has not been overcome and further understanding is needed to find sustainable solutions that operate at scale.

Transport and disposal is a common problem identified in numerous locations such as Maputo (Sugden, 2005), Nairobi (Bongi and Morel, 2005) and Dhaka (GHK, 2005). Transfer stations have been identified as an additional component that could help (Strauss and Montangero, 2002). These systems can be categorised into two groups, permanent and mobile. Mobile transfer stations include both tractor trailer arrangements and movable skips (Eales, 2005). There is significant difficulty in finding information on permanent installations, such as those found in Accra. 
Further work being conducted by the Department of Water and Sanitation in Developing Countries (SANDEC) at EAWAG in Switzerland views the problem of faecal sludge management (FSM) as a complex and inter-related mix of governance, financial flows, the role of the private sector and the lack of appropriate treatment facilities (Strauss and Montangero, 2002). The SANDEC research group, as well as the IWA's Sanitation 21 Task Force, acknowledge that dealing with faecal sludge cannot be solved entirely through technical means, but requires greater understanding and support to ensure faecal sludge management systems are in place (IWA, 2006). Emptying of latrines is only the beginning of the FSM chain and institutional support is essential to overcome problems that occur from collection through to treatment.

Schaub-Jones (2005) discusses the need for sanitation partnerships if the requirements of three different groups are to be met. One is the 'private good', involving households with toilets who need sustainable and acceptable sanitation. There is also the need to satisfy the 'provider's good' to ensure those who provide services are able to remain financially sustainable. Finally, it is important to satisfy the needs of the public through the fulfilment of the 'public good', as municipalities fulfil their obligation to ensure public health.

Accra, the capital city of Ghana, has a population of approximately 2.2 million people (World Bank, 2002). In contrast to other large African cities, there are still a significant number of bucket latrines in use around the city. Bucket latrines require regular emptying and typically offer an unsanitary sanitation system (Cotton and Saywell, 1998). They are considered an unimproved form of sanitation and therefore do not support the achievement of Millennium Development Goal (MDG) targets with respect to increasing access to improved sanitation facilities by 2015 (JMP, 2006). In efforts to improve the bucket latrine system in Accra (without replacing the buckets), Scott Wilson and Taylor Woodrow, with funding from the UK's Department for International Development, constructed 60 transfer stations (locally termed underground holding tanks (UHTs)) across the city in 1997/98, with bucket latrine emptying services privatised and official contractors registered to empty them.

\section{THE RESEARCH}

Research conducted in 2007 aimed to assess the existing arrangement for faecal sludge management in Accra, where bucket latrine emptying services are carried out both by registered contractors and illegal operators (Boot, 2007). Accra's provision of transfer stations and the privatisation of collection services was viewed as an good case study from which to explore potential areas for improvement in the transportation of faecal sludge, lessons from which could be refined through a more detailed assessment of the situation in Accra and further comparison with services elsewhere.

\section{Methodology}

The research was conducted using a series of structured, semi-structured and focus group interviews with private operators, government officials, external support agencies and Accra Metropolitan Assembly (AMA). Findings were triangulated where possible using observations, published and unpublished literature, verification of data through calculations and interviews with other stakeholders.

\section{RESEARCH FINDINGS}

The population of Accra relies significantly on three main types of sanitation facility. These are:

- household latrines connected to on-site septic tanks (in higher income households);

- household bucket latrines (known locally as 'pan latrines' and used extensively in the poorer communities); and

- communal latrines connected to septic tanks (located around the city, with high numbers in poor areas). 
Exact numbers and coverage figures of each type of facility are not known. The AMA aims to completely phase out the use of bucket latrines within the city by 2010 , but numerous problems are foreseen with this proposal. Some of these are discussed later.

In order to safely dispose of faecal sludge collected from households, the sludge must be removed from a facility, transported to a point of disposal (which could be a holding tank at an intermediate transfer station, requiring further collection, transport and disposal), then ideally undergo some form of treatment of the sludge and final safe disposal of the by-products. The research findings from Accra will be presented in this paper under these sub-headings: emptying, transport, disposal and treatment.

\section{Emptying}

Emptying of the sanitation facilities in Accra typically occurs in one of two ways. Firstly, large vacuum tankers are used to empty the vast majority of septic tanks found throughout the city. These are typically imported, European-manufactured tankers, costing approximately US $\$ 110,000$ each (Armah, 2007). The alternative method that is heavily relied on is the manual emptying of bucket latrines in the poorer areas of the city. This method involves carrying the bucket from the household to one of the underground holding tanks at the transfer stations strategically located around the city (see the later section on disposal).

One private contractor emptying bucket latrines uses small tankers (called Dung Beetles manufactured in Denmark, see Figure 1) that are designed to operate in the densely populated poor areas of the city. The equipment allows the operator to pump faecal sludge directly into the tanker, without having to manually handle the contents. The Dung Beetles, despite their relatively small size, still experience problems when accessing some of the more densely populated parts of Accra..

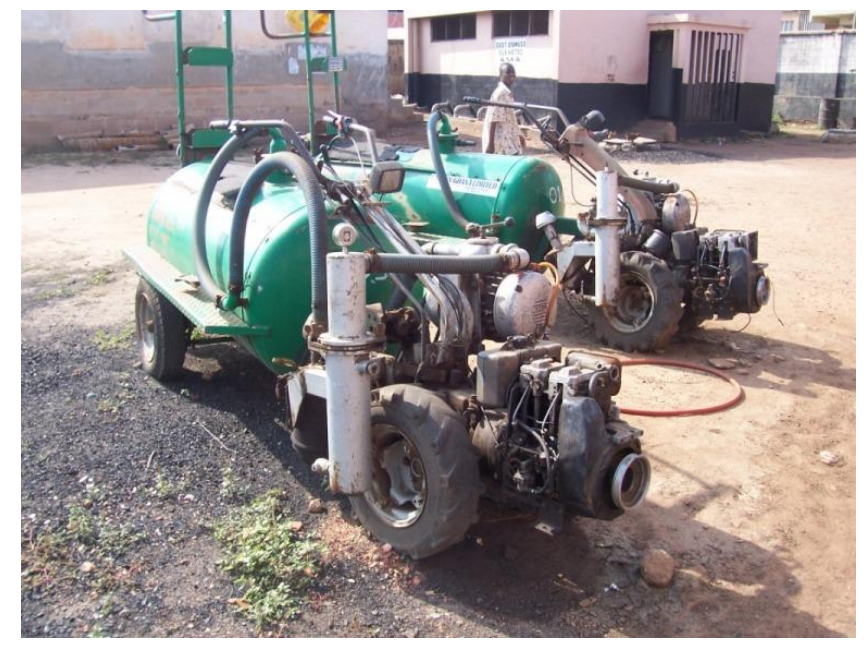

Figure 1 - Dung Beetle machine (Photo: Niall Boot)

Pit emptying is a very common practice in other African cities, where pit latrines are used extensively. But given the relatively small number of pit latrines found in Accra, no manual emptying of pit latrines (whereby a worker enters the pit to dig out the contents) was reported during the research (Boot, 2007).

Private vacuum tanker operators. There are approximately 50 private companies in Accra that provide septic tank emptying services in the city. Some of these companies also empty the communal latrines of the city - although these facilities put an increased strain on the vacuum 
pumps, due to the thicker nature of the faecal sludge. Water is often added to liquefy the sludge slightly, which is then mechanically agitated, before removing it.

These private operators are can still make a small profit. Through interviews held with private tanker operators, it was suggested that the profit made from an average trip to empty and dispose of faecal sludge using a 7,000 litre tanker, ranges between US\$10-23. The largest outgoings associated with operating the tankers are attributed to the fee charged by the Waste Management Department (the department of the Accra Metropolitan Assembly responsible for FSM) to dispose of faecal sludge at one of two official tipping points and the cost of diesel. The number of trips made by a single 7,000 litre tanker varies from 2-4 each day. A higher number of trips occur in the rainy season, possibly as a result of poor septic tank construction allowing the ingress of surface water runoff to rapidly fill the tanks.

Public sector vacuum tanker operations. The Waste Management Department (WMD) used to operate six vacuum tankers purchased with funds from the UK Department for International Development (DFID) in the 1990s. Over the years however, these have gradually broken down and in 2007 only one remained in operation, predominantly servicing public buildings. The vacuum tankers were originally meant to service the transfer stations / underground holding tanks (UHTs), which exist in the areas of the city served by bucket latrines. The task of operating them has now been unofficially transferred-over to the private sector.

Bucket latrine contractors. In 1997 the official responsibility for emptying bucket latrines was handed over to the private sector by the WMD. A number of contractors were appointed certain areas of Accra in which to operate. Originally 9 registered contractors operated such services. As a result of unsanitary practices, a number of contractors did not have their licenses renewed and currently only 5 contractors remain in operation.

The majority of these contractors collect faecal sludge manually from households, carrying the buckets to one of the transfer stations, where the waste is disposed into the UHT. It is then the responsibility of a private vacuum tanker operator to remove the sludge from the UHT, the cost of which is covered through fees paid by the bucket latrine contractor.

Illegal bucket latrine emptiers. There are an unknown, but significant number of informal (and, due to the local by-laws concerning emptying operations, therefore illegal) emptiers operating across Accra city. Due to poor regulation and night-time working hours, the exact number of these informal/ illegal operators is unquantifiable. Official bucket latrine contractors report that this illegal sector can operate at rates that undercut the official AMA tariff for emptying, making it more difficult for the registered, private operators to retain their customer base.

\section{Transport and disposal}

There are essentially two sites for faecal sludge disposal in the city; the underground holding tanks (UHTs) used by bucket latrine contractors, and the designated 'tipping points' used by the vacuum tanker companies. The illegal pan latrine contractors practice uncontrolled disposal, directly into the urban environment - this could be viewed as a third 'site'.

Underground holding tanks (UHTs). The UHTs were constructed during the mid 1990s as part of a much larger support programme for sanitation in Accra that included the construction of the wastewater treatment works. Prior to the construction of the UHTs, covered skips - typically used for the storage of solid waste - were used to collect faecal sludge. Contractors would empty the contents of bucket latrines into these skips, but difficulties in lifting the buckets meant that contents were often spilt. The UHTs aimed to improve emptying and reduce the resulting odour and fly 
nuisance of the skips, by building the UHTs below ground and including a dedicated ventilation pipe (as shown in Figure 2).

The UHTs appear to have achieved the original aims for improving collection and emptying of faecal sludge locally, although occasional shortages of vacuum tankers to ensure regular emptying of their contents for final disposal, results in overflowing of the UHTs. Furthermore the UHTs face problems with siltation of the waste over time. This necessitates manual de-silting which is an expensive processing involving a crane to remove the heavy concrete lid.

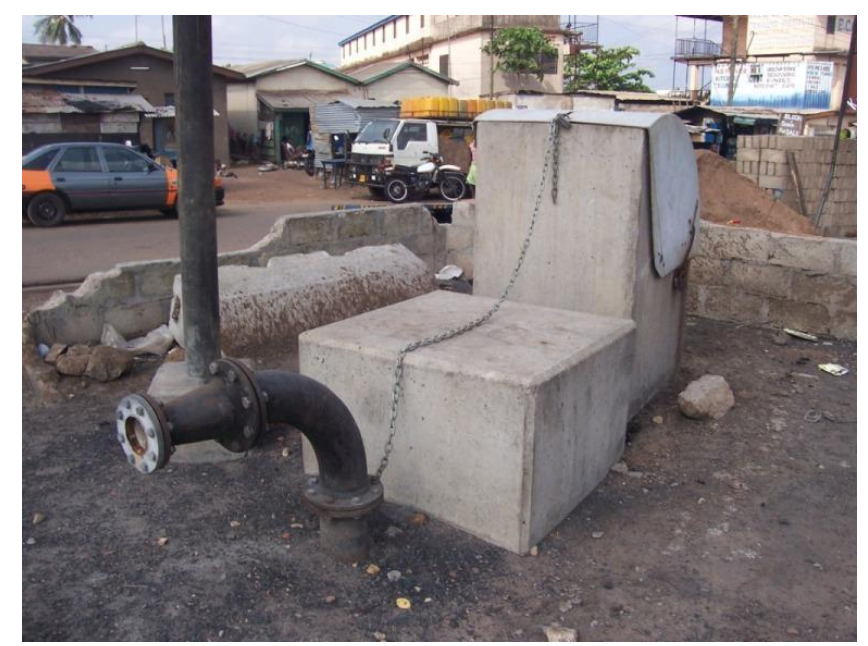

Figure 2 - An Underground Holding Tank (Photo : Niall Boot)

Tipping points. There are currently only two locations where vacuum tankers are officially allowed to dispose of collected faecal sludge (see Figure 3). At Korle Gono (where approximately $83 \%$ of faecal sludge is disposed), the tankers discharge sludge either directly into the ocean or onto surrounding land. At Teshie tipping point, tankers discharge sludge into waste stabilisation ponds. These however have silted up, preventing their effective operation. An additional set of waste stabilisation ponds used to exist in the north of Accra. These however have been closed, reportedly to make way for a new shopping centre.

The result of this closure is an increase in the transport distances between many of the service customers who live in the north of the city and the disposal sites along the coast, resulting in an increase in diesel costs. The longer turn-around times has lead to a reduction in the number of potential customers per day - affecting financial viability of operations. 


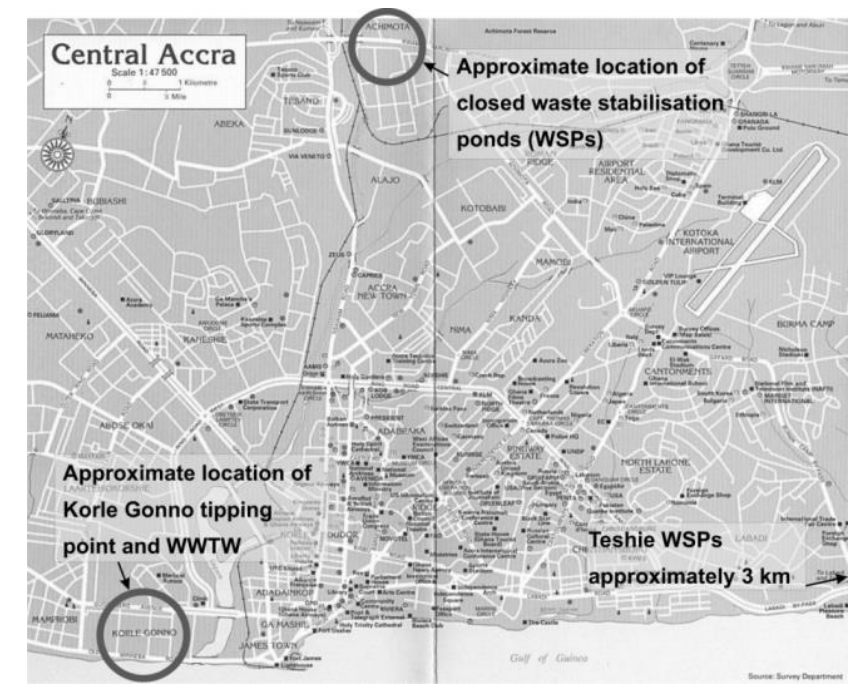

Figure 3 - Layout of Accra and location of the two tipping points

\section{Treatment}

The treatment facilities in Accra are totally inadequate. A large donor-funded programme in the 1990s included the construction of a sewage treatment works, but this has not been operating for some time. Damage to the intake pumps has not been addressed for many years and currently sewage from the city's central business district is discharged to the ocean without treatment. The situation at Korle Gono tipping point is further adding pollution to the ocean and the wider environment.

\section{DISCUSSION}

Three key outcomes from the research conducted in Accra can be identified as:

- the level of income households appear to be spending on emptying services,

- the phasing-out of bucket latrines and obstacles facing this move; and

- the role of the public sector in the ongoing provision of emptying services.

\section{Household expenditure on emptying services}

Vodounhessi (2006) assesses that householders should allow up to $0.5 \%$ of their income for faecal sludge management services (a proportion of the WHO recommended 5\% standard for all WATSAN services). The current charge in Accra of US $\$ 11$ per household per month for emptying a bucket latrine (see Table 1) represents $0.5 \%$ of US $\$ 26,400$ per annum. This is obviously a far higher income than the average annual household income. In 1999, average household income was found to be US $\$ 409$ per annum for the poorest $20 \%$ of Ghana's population and US $\$ 1,462$ per annum for the population of Accra (TUC, 2004).

This suggests that poorest households are paying up to 65 times the recommended level and a far higher proportion of their household income than is recommended by the WHO. This suggests that households are prepared to pay excessive costs as a means to secure regular and reliable latrine emptying services, despite the latrine offering a very low level of service.

Costs incurred by septic tank owners are much more variable, resulting from the unpredictable filling rate, tank volume and number of householders sharing one septic tank. The cost to a household for emptying septic tanks is estimated to be within the range of approximately US\$60-340 per annum. Again, this is likely to represent a significant proportion of household income, suggesting that households will and do pay high charges to secure a reliable emptying service. 
Table 1. Key charges for emptying sanitation facilities in Accra (2007)

\begin{tabular}{|l|l|}
\hline Task & Cost in Ghana Cedis per trip \\
\hline 7,000 litre vacuum tanker emptying a pit/UHT & 46 (US\$ 50) \\
\hline 7,000 litre vacuum tanker emptying a domestic septic tank & 52 (US\$ 57) \\
\hline Emptying a bucket latrine (fixed monthly fee) & 10 (per month) (US\$ 11) \\
\hline Disposal charge for vacuum tankers at tipping point & 12 (US\$ 13) \\
\hline
\end{tabular}

Source: Waste Management Department records, 2007

Comparing costs in Accra with charges for emptying latrines by the privately operated vacuum tankers in other cities indicates implications for household expenditure are fairly typical. In Dar es Salaam, Tanzania mechanical emptying of pit latrines was found to be US\$20-25 per trip for a 5-8 $\mathrm{m}^{3}$ tanker (BPD, 2006). In Freetown, Sierra Leone costs can vary, depending on pit location in relation to disposal sites, between US\$ 40-60 (Atkins et al, 2008).

Putting these values into context alongside average urban Ghanaian household cash expenditure on other items is informative. A report by the Ghanaian statistical service in 2000 (Asenso-Okyere et al, 2000) shows average urban household annual expenditure in Ghana to be approximately 220 Ghana Cedis on food and beverages (just under 18 Ghana Cedis per month) and approximately 20 Ghana Cedis on medical care and health expenses (less than 2 Ghana Cedis per month).

\section{Bucket latrines: an unsanitary system}

The bucket latrines used in Accra, as in many other locations, typify an unsanitary system. The practice of emptying them is usually undertaken by illegal operators - marginalized members of the community who typically operate under cover of darkness. This allows them to operate without being recognized, as residents would not consider the alternative acceptable. In order to dramatically improve sanitation provision, Accra must carefully consider suitable alternatives to the bucket latrine system. Alternatives are presently limited to the Kumasi Ventilated Improved Pit (KVIP) latrine, or septic tanks. These both have limitations for sustainable operation in poor urban areas, as:

- vacuum tankers will not be able to access the facilities for emptying, due to the congested nature of properties and resulting limited access to household latrines;

- residents are unlikely to have the disposable income available to meet the cost of materials (a system of payment being proposed by the WMD for construction); and

- space is often too valuable in poorer areas to construct such sanitation facilities, if any land is available. Where communal latrine blocks are present, this reduces the pressure and the incentive for households to construct an individual family alternative.

A key challenge facing urban sanitation provision results from emptying problems associated with low-cost, on-site latrines. Many such latrines have been constructed when space was once available, without consideration for later adjustments as this space becomes less available and emptying becomes both increasingly challenging and more critical. In Accra there is little space to replace bucket latrines with larger installations. Despite this, emptying continues to take place - albeit it in an unsanitary manner - in a way that offers lessons for other African cities. 
Faecal sludge, once removed, is disposed of into transfer stations that are then emptied routinely. In many cases, it is the presence and operation of the informal sector that results in faecal sludge reaching the immediate urban environment. While the emptying system continues to work relatively successfully, an improvement in access, operation and management of UHT installations themselves and an improvement of the bucket latrine facilities is desirable.

Conversion of bucket latrines was part of a pilot project conducted by the operators of the Dung Beetle machines, mentioned previously. The aim of this conversion project was to exclude the illegal sector from emptying latrines, by installing a fibreglass box at each household to which only Dung Beetle machines would be able to connect to remove the faecal sludge. This introduced obvious risks to the household if, for example, the Dung Beetles were to breakdown (as did occur). Consequently, the contents of the boxes overflowed into households, or the illegal sector operators would return and break open the boxes to gain access to the waste. Scaling up this system beyond a small scale pilot is therefore not considered to be advisable.

However, a well thought-out conversion programme (possibly resulting in less frequent emptying requirements) could enhance the situation significantly, offering improvements at the household level whilst reducing the uncontrolled operation of the illegal sector. To ensure that both the new system could work well and that the whole faecal sludge management chain would operate effectively, further improvements are required in the role and function of the public sector (see below).

The presence of communal latrines exacerbates the problems associated with the process of conversion from bucket latrines. People are less likely to adopt (or retain) a household option where communal facilities exist. However, conversely if communal latrines were to be removed, people may be left with no option but to practice open defecation, or very rudimentary sanitation (such as flying toilets).

\section{The role of the public sector}

There remains a lack of appropriate allocation of responsibility between the public and private sector in the FSM process in Accra. The underground holding tanks, while belonging to the public sector, operate effectively under the control of the private sector. There is generally a medium-level of engagement between the public and private sectors in this respect, with the transfer station system operating under a type of public-private partnership, without any direct involvement of donors or civil society.

The private sector is, however, simply working to empty pits, tanks and buckets across the city, ensuring they generate sufficient profit to remain in business. A focus group interview with several private vacuum tanker owners identified the range of costs for running an emptying service, including disposal fees, diesel, worker fees and maintenance costs. Given the likely income from a trip (US\$44-57) a profit of US\$10-23 per trip is possible (Boot, 2007).

In this respect, there are limitations in the effectiveness of the service provided by the public sector - resulting in a significant gap between poor households and those responsible for monitoring, regulating and setting tariffs for services. The problems resulting at the interface between private and public provision - most clearly indicated by problems associated with operation of the transfer stations - highlights the necessity for better engagement, effective dialogue and the development of working relationships between all parties involved. 
Civil society involvement in urban sanitation has been exhibited in other cases around the world, such as the relative success of the support from a Bangladeshi NGO (DSK) in the management of faecal sludge in Dhaka, Bangladesh (GHK, 2005) and the role of a small-scale private operator in Bamako, Mali (Jeuland et al, 2004). What is missing to achieve the full potential from the public-private partnership between AMA and the private sector within Accra are aspects of facilitation and collaboration with the wider stakeholder group. There appears to be scope for this in Accra, as there is no clear operational role, or voice, for civil society in sanitation issues within Accra at present. The presence of an NGO, able to both facilitate and represent civil society in ongoing dialogue with the other key stakeholders, could even go so far as to facilitate representation of informal (currently illegal) bucket latrine contractors, as well as householders and other civil society groups.

The establishment of an umbrella NGO would help to strengthen the enabling environment for better government engagement with non-state providers of sanitation services (Scott and Sansom, 2006). The relative success of the DSK-supported vacutug service in Bangladesh lends further support to this, as does the example of Mvula Trust, an NGO in South Africa who facilitated engagement between small-scale informal sanitation operators and high-level decision makers (ibid, 2006).

\section{CONCLUSIONS}

The urban case for sanitation is infinitely more complex than in rural settings, with issues such as a lack of space for construction placing significant obstacles for the implementing agent. A move towards the recognition of the illegal operators, with their role incorporated into a wider plan of improving sanitation services to poor households in Accra, could allow them to enhance, rather than exacerbate, current operations of the registered service providers. Ideally, the UHTs would be made available for all bucket latrine workers to discharge excreta into. For this to be acceptable and sustainable, emptying of the UHTs needs to be a publicly regulated operation (even if the management is outsourced to private operators).

Reducing haulage distances, from households to the transfer stations and from these to the eventual disposal and/or treatment locations, could reduce costs placed on private sector operators. Analysis of the impact of such cost adjustments on operating profitability have not been carried out, but would be an important feature of any modifications.

\section{Lessons learned}

The research carried out in Accra has highlighted a number of key lessons, for consideration in other urban centres where Faecal Sludge Management improvements are being considered :

- Where forms of sanitation exist such as bucket latrines, that provide only a low level of service, any process for phasing them out must account for the means by which faecal sludge can be effectively and safely managed, before new facilities are introduced. The WMD's plan to utilise twin-pit latrines to replace pan latrines must also take into consideration the space available, costs and requirements for construction and subsequent emptying of the facilities.

- Maintaining a competitive environment for private sector operators should ensure best practice is followed, with an adequately capacitated public sector regulating and monitoring private operators. The ability of the AMA's Waste Management Department to issue and revoke licences reduces indiscriminate dumping away from pre-determined tipping points.

- Facilities such as intermittent transfer stations for temporary storage of faecal sludge help to enhance the operation of latrine emptiers, helping them provide services that are more costeffective and responsive to household needs. Access to such facilities should be made widely available, supported by good regulation and oversight. Transfer stations offer a potential point for the transfer of responsibility between private operators (who provide 
household and communal-level emptying services) and public operators (who are involved in transport, disposal and treatment services). The case in Accra provides a real look into what happens when large numbers of permanent transfer stations are installed and many lessons can be learnt for replication in other areas, given that there is general acceptance that the approach can improve services.

\section{Acknowledgements}

The authors would like to extend their thanks to Nat Armah, Peter Hawkins and David Schaub-Jones for assistance in the research work carried out in Accra, Ghana.

\section{REFERENCES}

Armah, Nathaniel (2007) (Retired, formerly head of Accra Metropolitan Assembly, Waste Management Department) Personal communication (E-mail/interview)

Asenso-Okyere, W.K., Twun-Baah, K.A., Kasanga, Adams, Anum, Jacqueline and Pörtner, Claus. (2000), Ghana Living Standards Survey, Report of the Fourth Round, Ghana Statistical Service, Accra, Ghana

http://www.worldbank.org/html/prdph/lsms/country/gh/docs/G4report.pdf

(Accessed 25 ${ }^{\text {th }}$ March 2008)

Atkins, Oxfam, 3BMD (2008) Strategic Water Supply and Sanitation Framework: Part 3 Sanitation Improvement Plan. Atkins Ltd, Surrey, England.

Bongi, Sabine and Morel, Alain (2005) Understanding Small Scale Providers of Sanitation Services: A case study of Kibera. Water and Sanitation Program (WSP), Kenya.

Boot, Niall L.D., (2007), Talking Crap: Faecal Sludge Management in Accra, Ghana, MSc research project, WEDC, Loughborough University, UK

BPD (2006), Sanitation partnerships: Dar es Salaam case study. Building Partnerships for Development (BPD), UK

http://www.bpd-waterandsanitation.org/bpd/web/d/doc_117.pdf?statsHandlerDone=1

(Accessed $9^{\text {th }}$ March 2008)

Cotton, Andrew and Saywell, Darren (1998), On plot sanitation in low income urban communities:

Guidelines, WEDC, Loughborough University, UK

http://wedc.lboro.ac.uk/publications/details.php?book=0\%20906055\%2055\%205\&keyword=\&subj ect=9\&sort=TITLE

(Accessed 20 $0^{\text {th }}$ March 2008)

Eales, Kathy (2005) Sanitation partnership series: Bringing pit emptying out of the darkness: A comparison of approaches on Durban, South Africa and Kibera, Kenya. Building Partnerships for Development.

GHK (2005) Decentralised domestic wastewater and faecal sludge management in Bangladesh. GHK Consulting Ltd, UK. 
IWA (2006), Sanitation 21, Simple Approaches to Complex Sanitation: A Draft Framework for Analysis, International Water Association, London, UK

http://www.iwahq.org/uploads/iwa\%20hq/website\%20files/task\%20forces/sanitation\%2021/Sanitati on21v2.pdf

(Accessed 20 $0^{\text {th }}$ March 2008)

Jeuland, Marc, Kone, Doulaye and Strauss, Martin (2004) Private sector management of faecal sludge: A model for the future? - Focus on an innovative planning experience in Bamako, Mali. Department of Water and Sanitation in Developing Countries (SANDEC), Switzerland.

JMP (2006), Meeting the MDG Drinking Water and Sanitation Target: The urban and rural challenge of the decade, Joint Monitoring Programme (JMP), WHO and UNICEF, Switzerland

Scott, Rebecca and Sansom, Kevin, (2006), Supporting Non-State Providers (NSPs) in Sanitation Service Delivery, WELL Task 2765, report for DFID, WELL, Loughborough University, UK. http://www.lboro.ac.uk/well/resources/well-studies/full-reports-pdf/task2765i.pdf

(Accessed $9^{\text {th }}$ March 2008)

Strauss, Martin and Montangero, Agnes, (2002), Faecal sludge management - a review of practices, problems and initiatives (GHK DFID KAR R8056: Capacity building for effective decentralised wastewater management), SANDEC, Switzerland

Sugden, S. (2005) An assessment of mechanical pit emptying services in Maputo. London School of Hygiene and Tropical Medicine (LSHTM), UK.

TUC (2004), Incomes in Ghana: Policy discussion paper. Trade Union Congress (TUC), Ghana http://www.gpn.org/data/ghana/ghana-analysis.doc

(Accessed $9^{\text {th }}$ March 2008)

Vodounhessi, Anselme (2006) "Ghana - Financial and institutional challenges to make faecal sludge management an integrated part of the ecological sanitation approach", in Snel, Mariëlle and Smet, Jo, The Value of Environmental Sanitation - Case studies. Occasional paper series 42. IRC International Water and Sanitation Agency, the Netherlands.

World Bank (2002) Upgrading urban low income settlements. Country assessment report Ghana. The World Bank. 
Click here to download high resolution image

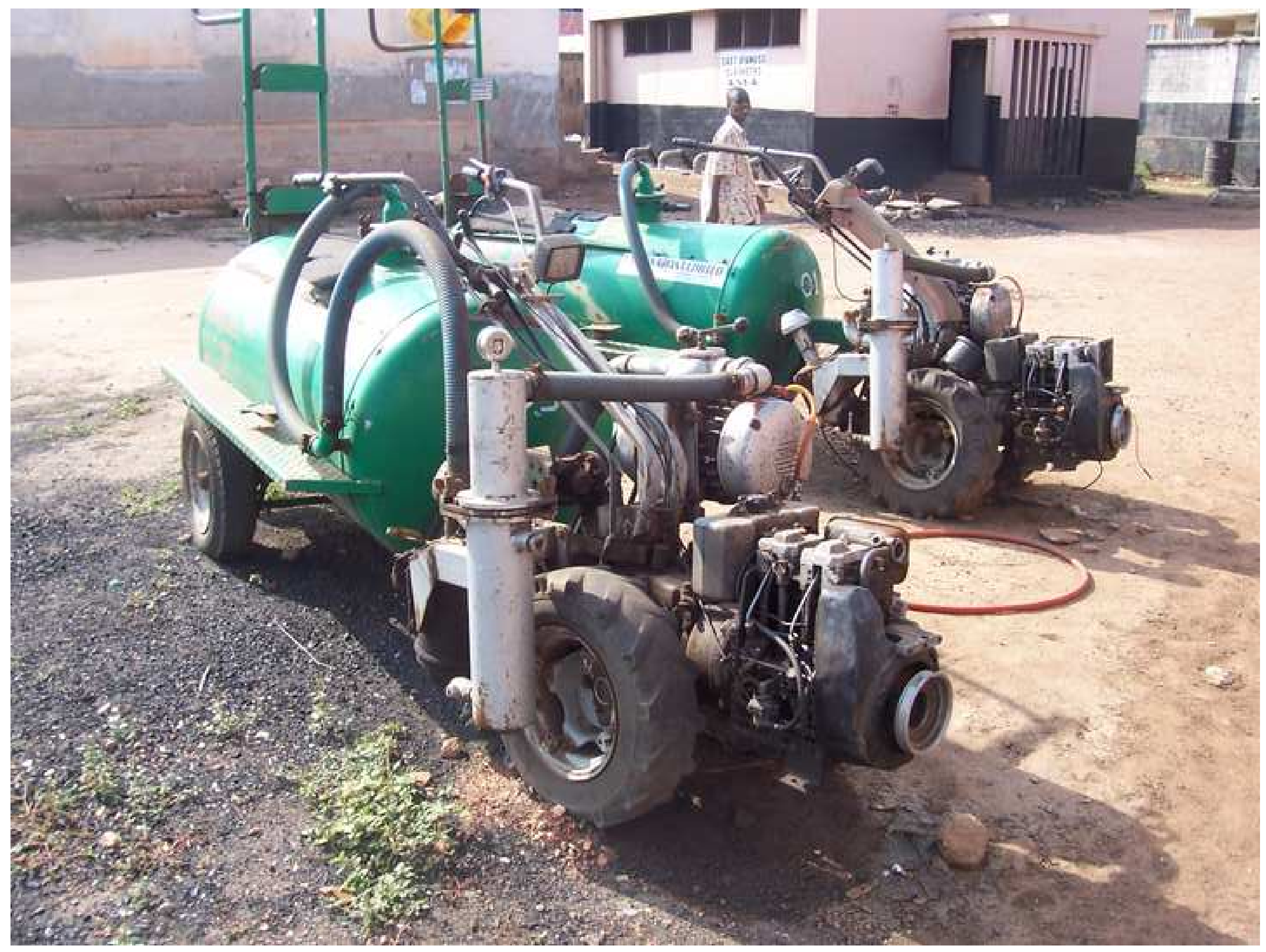


Click here to download high resolution image

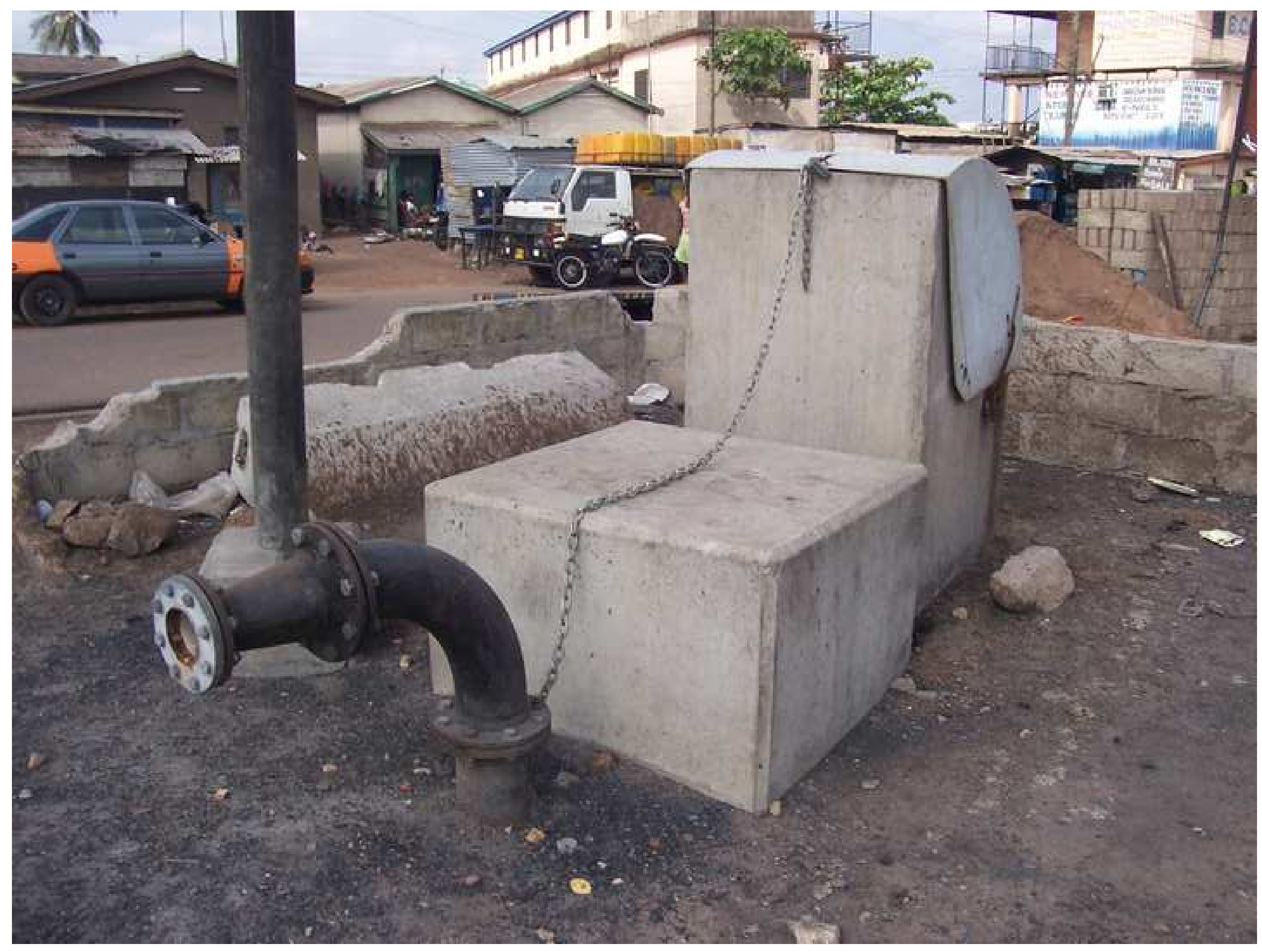

Figure 2 
Click here to download high resolution image

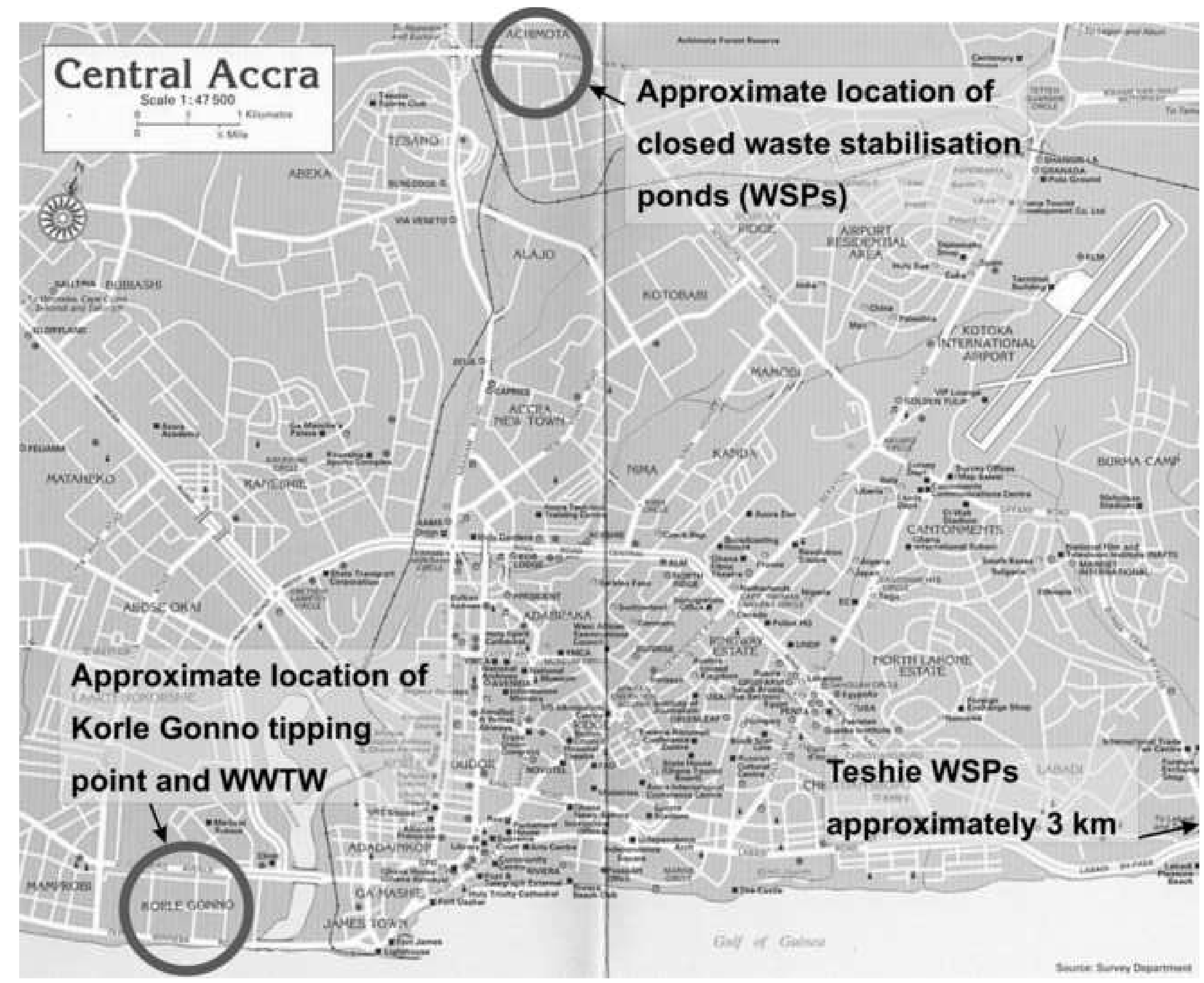

\section{.}

